\title{
Rare Morphology of The Third Maxillary Molar and Potential Complications in its Extraction
}

www.adum.edu.my

Ann Dent UM 2020, 27:66-68 Dol: 10.22452/adum.vol27no10

\author{
Siti Mazlipah Ismail ${ }^{1 *}$, Firdaus Hariri ${ }^{1}$
}

\section{KEYWORDS}

Maxillary third molar, Root morphology, difficult extraction

\section{ABSTRACT}

There is a wide variation in the morphology of third maxillary molar which can be difficult to be identified radiographically. We present a case of a 26 year-old Yemeni female patient presented with difficult extraction of her left maxillary third molar. The extracted tooth showed a rare variation of root morphology, having four roots with three roots curving palatally at the apices. This report emphasized the potential complex morphological variation of maxillary third molar which may lead to the difficulty of a routine straight forward procedure thus needing careful extraction maneuvering to prevent any complications.

\section{INTRODUCTION}

There is a wide variation in the morphology of the third maxillary molar which is very difficult to predict in radiographs [1]. It may present with three roots, which often fuse with each other, with one or two canals being evident [2].

Berkovitz el al. stated that the morphology of the maxillary third molar may resemble to some extent with the second maxillary permanent molar [3]. It usually presents with a triangular-shaped crown without talon. Its roots are irregular in shape and sizes and are often fused. It is often congenitally absent. However, these particular authors did not illustrate the tooth with diagrams as according to their opinions, as such; the morphology of the maxillary third molar varies greatly.

Zhang et al. studied the morphology of 130 maxillary permanent molars in a Chinese population. They found $51.5 \%$ had single fused

${ }^{1}$ Department of Oro-Maxillofacial Surgical \& Medical Sciences Faculty of Dentistry

*Correspondence: sitimazlipah@um.edu.my roots, only $19.2 \%$ had double roots while $25.4 \%$ had 3 roots [4]. Ditty et al. found that $28.79 \%$ of their 94 patients had dilacerated roots associated with the maxillary and mandibular molars [5]. They concluded that roots morphology is a significant consideration as to whether the tooth should undergo open or trans-alveolar extraction. The highly variable maxillary third molar root morphology is rarely elaborated in most publications $[6,7]$.

\section{CASE HISTORY}

A 26 year-old Yemeni female without relevant medical condition presented with a left maxillary third molar which was buccally inclined, over erupted and was impinging on the mandibular mucosa. The opposing mandibular third molar was absent. The maxillary third molar was indicated for extraction under local anaesthesia.

Radiographically the root appeared longish and conical in shape, and it was thought that extraction of the tooth would not pose any problem (Figure 1). During extraction, the authors encountered much difficulty in trying to remove the tooth. Even though the tooth had become mobile after the application of elevators and molar 
forceps, the tooth still could not be delivered. Only after much toil time, anxiety and patience, the tooth was finally delivered without fracturing the roots. A standard post-extraction instruction was given and the patient had an uneventful recovery.

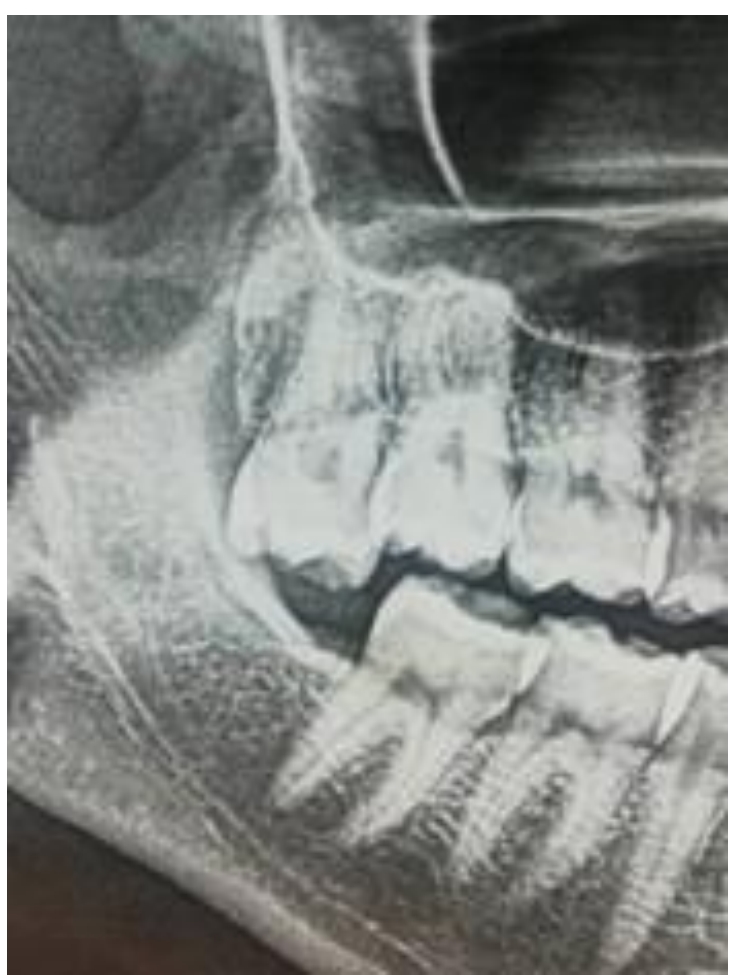

Figure 1: The maxillary third molar root appears conical and elongated.

\section{DISCUSSION}

Although the root of the tooth in question appeared conical radiographically, it was not so morphologically once it was out of the mouth. It had four roots with all three roots curving palatally towards the tip (Figure 2).

The presence of the three curved roots had significantly contributed to the difficulty of the extraction as the periodontal ligament space needs to be sufficiently widened in order to deliver the tooth without fracturing the root tips. The path of delivery was also complicated by the limited space and access which was partially obstructed by the coronoid process of the mandible when patient was asked to open mouth wide. A forceful and careless extraction could have fractured the small curved roots, resulting for them to be left behind and might even result in a maxillary tuberosity fracture.
During the extraction of the tooth, the authors experienced difficulty in delivering the tooth despite having rendered it quite mobile. The unexpected presence of four roots and curved tips were not predicted by the pre-extraction radiograph. However, careful extraction manoeuvre coupled with patience finally paid off.

The indications for upper third molar extraction include caries, unfavourable inclination and overeruption of non-functional maxillary third molar. The extraction of the maxillary third molar can usually be done without much struggle because they are usually small with convergent roots. The authors find the Warwick James elevators to be a useful instrument in most upper wisdom tooth trans alveolar extractions but this particular case required a different approach. However, Ditty et al. had stated that root morphology has a pivotal role in deciding on the need for a surgical extraction [5].
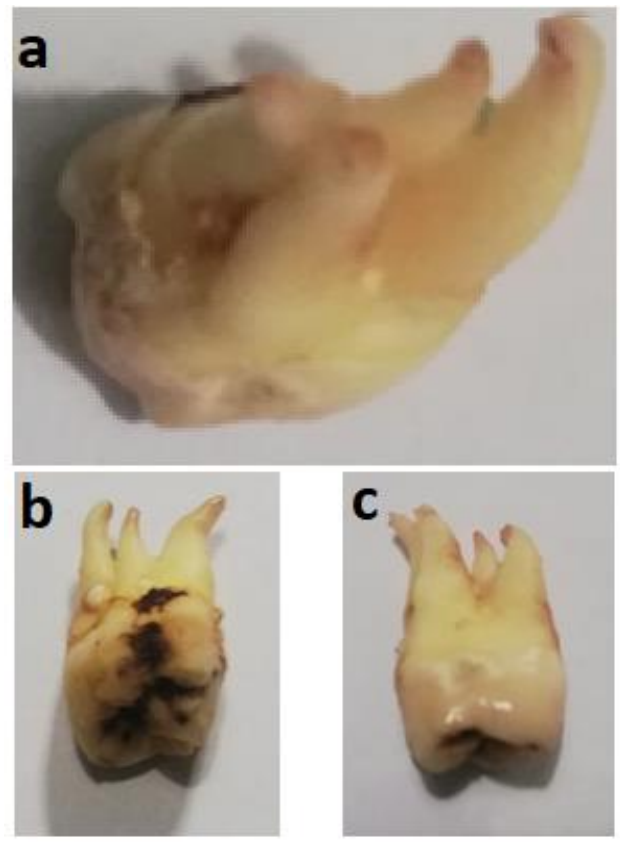

Figure 2: Root morphology of the extracted upper wisdom tooth. (a) Apical view with four roots clearly discernable. (b) Mesial view with three roots curving palatally. (c) Distal view with three roots curving palatally.

Complications of maxillary third molar extraction include fracture roots, fracture of maxillary tuberosity and oro-antral communication. Iwata et al. stated that maxillary third molars have a greater chance of causing oro-antral communication during extraction if the relation of the third molar crown is more apical than the second molar's occlusal plane (Archer Type B,C,D) 
or when there is scalloping or overlapping of the maxillary sinus lining around the premolar and molar roots (RS classification Type II/IV). [6] A rare complication of maxillary third molar being displaced into the infratemporal fossa in what was seemingly a usual extraction of the tooth was reported by Mace et al. [7]

\section{CONCLUSION}

Our report showed that maxillary third molar may present with morphological root variations which can be difficult to be identified radiographically. Even though the extraction of maxillary third molar is usually straight forward, any difficulty encountered during its extraction should be managed with care to prevent untoward complications.

\section{ACKNOWLEDGEMENT}

The authors would like to acknowledge the authors and publishers of all those articles and journals that has been cited in this manuscript.

\section{DECLARATION OF INTEREST}

The author reports no conflicts of interest. The author alone is responsible with the contents of the article.

\section{REFERENCES}

1. Tronstad L. Clinical Endodontics. A textbook. George Thieme Verlag, New York. 1991:195.

2. Stock C, Walker R, Gulabivala K. Endodontics. 3rd ed, Elsevier Mosby, Edinburgh. 2004:131.

3. Berkovitz BKB, Holland GR, Moxham BJ. Oral anatomy, histology and embryology. Mosby Elsevier, Edinburgh. 2009:22.

4. Zhang W, Tang Y, Liu C, Shen Y, Feng X, Gu Y. Root and root canal variations of the human maxillary and mandibular third molars in a Chinese population: A micro-computed tomographic study. Arch Oral Biol. 2018;95:134-140.

5. Ditty JM, Murugam S, Kareem N. Root morphology of maxillary and mandibular third molars - a potential cause for trans-alveolar extractions. Int J Res Pharm Sc. 2020;11(3):1393-1398.

6. Iwata E, Hasegawa T, Kobayachi M, Tachibana A, Takata N, Oko T, et al. Can CT predict the development of oroantral fistula in patients undergoing maxillary third molar removal? Oral Maxillofac Surg. 2020. https://doi.org/10.1007/s10006-020-00878-z

7. Mace $T$, Khan A, Dechaufour $P$, Kun-Darbois JD. An extremely rare case of a displaced third molar into the infratemporal fossa associated with a textiloma. J Stomatol Oral Maxillofac Surg. 2020;121(6):746-748.

\section{Editorial History}

Date of Submission: 22-12-2020

Review and Revision: 24-12-2020

Accepted: 24-12-2020

Published: $26-12-2020$

License Information: This work is licensed under a Creative Commons Attribution 